\title{
Mudanças no padrão de conduta do transplante de córnea após campanha informativa
}

\author{
Education and pattern behavior on corneal donation
}

Manuela Fiorese Benites ${ }^{1}$, Mariana Sponholz Araujo ${ }^{2}$, Ilana Barrichello Torres ${ }^{2}$, Geraldo Fraga Santini Canto ${ }^{3}$, Ricardo Cebrian ${ }^{4}$, Hamilton Moreira $^{5}$

\begin{abstract}
Resumo
Objetivo: Confrontar informações obtidas sobre doação de córneas através de questionários aplicados antes e após a realização de um ciclo de palestras informativas aos profissionais da área de saúde. Verificar o grau de conhecimento destes profissionais de hospital universitário em relação a informações básicas sobre o transplante de córnea. Documentar a reação pessoal destas pessoas frente ao procedimento. Métodos: Foi realizada uma campanha através de aulas com material audio visual específico trazendo informações detalhadas sobre o processo de doação e transplante de córneas. Estas palestras foram direcionadas a 115 profissionais da área de saúde: 46 médicos e 69 acadêmicos de medicina. Para a avaliação foi elaborado um questionário, aplicado antes e depois das aulas com intervalo de 1 mês, composto de 7 perguntas referentes ao procedimento do transplante em si, e 3 perguntas direcionadas à posição pessoal do médico em relação à doação de córneas. Resultados: Inicialmente obteve-se $61,72 \%$ de acertos nas perguntas objetivas, aumentando para 77,70\% após o acesso às palestras. Nas perguntas subjetivas a porcentagem de profissionais que doariam suas córneas foi $91,5 \%$, subindo para $93 \%$ após as aulas. De forma semelhante o número que autorizaria a doação de córnea de um familiar aumentou de $91,5 \%$ para $94,4 \%$. Quando questionados se já haviam abordado uma família espontâneamente e solicitado o procedimento de doação de córneas a resposta foi positiva em $4,8 \%$ dos profissionais avaliados, e esta porcentagem subiu apenas para 5,5\% após a realização das palestras. Conclusão: O despreparo dos profissionais de saúde em relação aos vários aspectos que concernem o transplante de córneas é nítido. Iniciativas isoladas como palestras informativas, apesar de necessárias, não são suficientes para mudar esta realidade.
\end{abstract}

Descritores: Transplante de córnea; Doadores de tecidos; Listas de espera; Conhecimentos, atitudes e prática em saúde; Questionários

\footnotetext{
${ }^{1}$ Residente em Oftalmologia do Hospital Universitário Evangélico de Curitiba - HUEC - Curitiba (PR), Brasil;

${ }_{3}^{2}$ Acadêmico da Faculdade Evangélica do Paraná - FEPAR - Curitiba (PR), Brasil;

Acadêmico da Universidade Positivo - Curitiba (PR), Brasil;

${ }_{5}^{4}$ Especializando em Oftalmologia do Hospital Universitário Evangélico de Curitiba - HUEC - Curitiba (PR), Brasil;

Professor Adjunto da Universidade Federal do Paraná - UFPR - Curitiba (PR), Brasil; Professor Titular da Faculdade Evangélica do Paraná

- FEPAR - Curitiba (PR), Brasil.

Trabalho foi realizado no Hospital Universitário Evangélico de Curitiba - HUEC - Curitiba (PR), Brasil.
}

Recebido para publicação em: 30/3/2008 - Aceito para publicação em 11/7/2008 


\section{INTRODUÇÃO}

$\mathbf{U}$ $\mathrm{m}$ dos procedimentos cirúrgicos de maior importância na oftalmologia moderna é o transplante de córneas, afinal, a recuperação da capacidade visual de um indivíduo influi diretamente em sua qualidade de vida e capacidade laborativa ${ }^{(1)}$.

Na atualidade, o transplante de córnea é a modalidade mais comum de transplante de tecidos ${ }^{(2.3)}$. Entretanto, o número de cirurgias desse tipo ainda é pequeno em relação à demanda de pacientes aguardando por este tratamento.

A lista de espera para o transplante de córnea em 2006, no Brasil, era de 24.549 córneas, sendo que somente no Paraná esse número ultrapassava 1.459 córneas. Para este mesmo período, o tempo de espera pelo transplante era de aproximadamente 1 ano e seis meses ${ }^{(4)}$.

Esta falta de doadores não é real, uma vez que o número de potenciais doadores se apresenta muito maior do que o número de córneas captadas. Segundo estimativa norte-americana, publicada em 1990, dos 20.000 potenciais doadores que vão a óbito por ano apenas 3.000 doaram efetivamente algum órgão ${ }^{(5)}$. Tal quadro também é constatado no Brasil, onde o problema é ainda mais grave. Essa situação parece ser reflexo da falta de informações tanto por parte da população quanto da classe médica ${ }^{(2-6)}$.

A retirada da córnea só pode ser realizada a partir do momento em que a doação é autorizada pela família do doador cadáver por escrito ${ }^{(7)}$. A doação espontânea depende da lembrança de algum familiar do doador a respeito desta possibilidade. Essa pessoa, então, precisa entrar em contato com os profissionais envolvidos no processo de morte e funeral para que autorize a doação e sejam realizados os procedimentos legais. Estas pessoas devem estar bem orientadas e preparadas para corresponder adequadamente à esta demanda. De outra forma, há a abordagem pró-ativa, na qual um profissional capacitado entra em contato com o familiar que quer realizar a doação para que esta seja efetivada.

Os objetivos do nosso trabalho são confrontar informações obtidas sobre doação de córneas através de questionários aplicados antes e após a realização de um ciclo de palestras informativas aos profissionais da área de saúde. Verificar o grau de conhecimento destes profissionais de hospital universitário em relação a informações básicas sobre o transplante de córnea. Documentar a reação pessoal destas pessoas frente ao procedimento.

\section{Métodos}

Trata-se de um estudo transversal, com dados obtidos através da aplicação de questionários entre médi-

\section{Gráfico 1}

\section{Porcentagem de acertos antes e após as palestras}

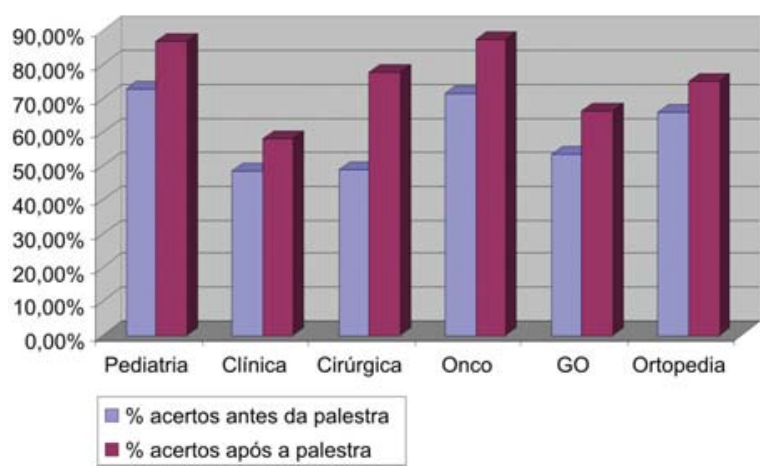

Legenda: Clinica $=$ Clínica Médica, Onco $=$ Oncologia, GO = Ginecologia e Obstetrícia

cos e estudantes de medicina.

Para realizarmos a pesquisa, seis especialidades médicas foram selecionadas levando em conta o volume de pacientes: clínica médica, clínica cirúrgica, ginecologia e obstetrícia, pediatria, ortopedia e oncologia.

Foi elaborado um questionário contendo 10 perguntas. A primeira parte era composta de sete perguntas referentes ao procedimento da doação e transplante de córneas tais como: qual o tempo necessário para a retirada de córneas, quais as contra-indicações, etc; e na segunda, através de três perguntas, o enfoque foi direcionado à reação pessoal do médico em relação à doação de córneas (Questionário 1).

Este questionário foi distribuído para os grupos e somente após o recolhimento dos mesmos foi realizada a aula informativa padronizada sobre $\mathrm{o}$ assunto. Estas aulas foram ministradas durantes o mês de outubro de 2006.

Decorrido 1 mês da explanação inicial, reaplicaram-se os questionários para os mesmos setores.

Finalmente os dados obtidos antes e após o ciclo de palestras foram analisados, comparados e confrontados com a literatura.

\section{Resultados}

Participaram do estudo 115 profissionais da área de saúde: 46 médicos e 69 acadêmicos de medicina. Nos questionários realizados anteriormente às palestras obtivemos $61,72 \%$ de acertos nas perguntas objetivas. Esta porcentagem aumentou para 77,70\%,1 mês após as palestras. Os escores discriminados por especialidade encontram-se no Gráfico 1, assim como a diferença percentual entre as duas etapas do trabalho. 


\section{Questionário 1}

FORMAÇÃO: ( ) Médico ( ) Residente ( ) Acadêmico de medicina ( ) Outros

IDADE:

ESPECIALIDADE:

1. MARQUE COM UM (X) AQUELES QUE NÃO PODEM SER DOADORES DE CÓRNEA?

( ) Pacientes hipertensos e diabéticos

( ) Pacientes com septicemia

( ) Pacientes com icterícia

( ) Paciente com miopia ou astigmatismo

( ) Paciente hepatite B ou HIV.

2. QUAL A IDADE MÍNIMA e MÁXIMA PARA SER DOADOR?
A) 16 e 60 anos
B) 18 e 55 anos
C) 21 anos e 45 anos
D) Não há idade mínima nem máxima

3. QUAL TEMPO MÁXIMO ENTRE A MORTE E A RETIRADA DAS CÓRNEAS PARA QUE ESTAS SEJAM VIÁVEIS?
A) 2 horas
B) 6 horas
C) 12 horas
D) 24 horas

4. QUANTO TEMPO DURA O PROCEDIMENTO DE RETIRADA DAS CÓRNEAS?
A) $15 \mathrm{~min}$
B) $30 \mathrm{~min}$
C) 1 hora
D) $1 \mathrm{~h} 30 \mathrm{~m}$

5. QUAL O ASPECTO DO DOADOR APÓS A RETIRADA DAS CÓRNEAS?
A) Alterado
B) Desagradável
C) Normal

6. PARA ONDE VAI A CÓRNEA RETIRADA?

A) Diretamente para o receptor

B) Para um banco de olhos

C) Para o hospital onde o paciente faleceu

7. APÓS A AUTORIZAÇÃO, ONDE A CÓRNEA PODE SER RETIRADA?
A) Somente no centro cirúrgico ou em ambiente estéril
B) No IML
C) $\mathrm{Na}$ capela
D) $\mathrm{Na}$ casa do paciente
E) Todas estão corretas

\section{VOCÊ DOARIA SUAS CÓRNEAS?}

( ) $\operatorname{Sim}$ ( ) Não

9. VOCÊ AUTORIZARIA A DOAÇÃO DE UM FAMILIAR?

( ) $\operatorname{Sim}$ ( ) Não

10. JÁ SOLICITOU ALUGUMA DOAÇÃO?

( ) Sim . Quantas vezes?__ ( ) Não 
Em relação às perguntas pessoais realizadas na primeira etapa, observamos que de todos os médicos e acadêmicos abordados, 91,5\% doariam suas córneas, 91,5\% autorizariam a doação da córnea de um familiar e apenas $4,8 \%$ já haviam solicitado alguma doação.

Já na segunda etapa, o número de doadores de suas próprias córneas aumentou para 93\%, a autorização da retirada da córnea de um familiar cresceu para 94,4\% e a experiência de solicitar a doação subiu para 5,5\%.

\section{Discussão}

Os profissionais de saúde são de fundamental importância no aumento do número de doadores de órgãos e tecidos. Segundo Mack et al. a falta de conhecimento dos mesmos a respeito do processo está diretamente relacionada à não procura de doadores, dificultando o contato da família dos potenciais doadores com as centrais de doação de órgãos ${ }^{(8)}$. Esta relação se faz presente, uma vez que, o médico que carece de informações a respeito do tema acaba apresentando receio em abordar a família do possível doador, conforme foi constatado no estudo de Ishay et al. ${ }^{(9)}$. Da mesma forma, Alves et al. concluiu em seu estudo, que a familiaridade dos médicos em relação à legislação brasileira e aos vários aspectos médicos do transplante de órgãos era insatisfatória ${ }^{\left({ }^{(6)}\right.}$.

Além disso,em nosso estudo foi constatado um relativo despreparo dos médicos e acadêmicos em relação a todos os aspectos que concernem ao transplante de córnea.As especialidades menos preparadas foram a de Clínica Médica e Clínica Cirurgica, justamente as áreas que possuem mais contato com patologias de alto índice de mortalidade.

Este desconhecimento é lamentável, já que um estudo de 1998, realizado por Ferreira et al. na Central de Captação de órgãos da Unicamp, mostrou que o nosso país possui uma das menores taxas mundiais de recusa familiar da doação de órgãos, porém se nenhum profissional abordar a família, não haverá a doação ${ }^{(10)}$.

Os acertos aumentaram em todas as especialidades após as aulas, demonstrando que estas foram adequadas para a função de informar. Porém, o aumento na solicitação da doação de córneas foi muito pequeno, o que mostrou que a campanha informativa isoladamente não foi eficaz e que há necessidade de investimentos nesta área.

\section{CONCLUSÃo}

O nível de conhecimento sobre o transplante e doação de córneas aumentou em todas as especialidades envolvidas, porém de maneira discreta. Através da avaliação foi verificada a relativa falta de preparo dos profissionais de saúde em relação à doação e transplante de córneas. De forma semelhante, a reação pessoal destes profissionais foi pouco favorável à doação de suas córneas ou das de seus familiares.

Esta realidade evidencia que apesar dos resutados do ciclo de palestras informativas, há necessidade da preparação de equipes especializadas para realizar a abordagem e contato com as famílias de potenciais doadores, para que haja um aumento no número de doações e, conseqüentemente, no número de pacientes beneficiados através deste procedimento.

\section{Abstract}

Objective: To compare obtained data about cornea donation through a questionnaire applied before and after the realization of an expositive lecture given to health professionals. To identify these professional's knowledge about basic cornea transplant information. To verify their personal reaction towards the procedure.Methods: A campain was performed using specific audio-visual classes about the cornea transplant's and donation process. These lectures were directed to 115 health professionals: 46 doctors and 69 medical students. For the evaluation a test was created and applied before and after the classes, with a one month break. This test included 10 questions, 7 about cornea transplant's specific information, and the other 3 were about their donation's opinion. Results: The questions about the procedure were corrected $61,72 \%$ at the first application and 77, 70\% at the second, answered a month later than the first. At the subjective questions the percentage of professionals that would donate their corneas was $91,5 \%$, increasing to $93 \%$ after the classes. In a similar way, the number that would authorize a family's cornea donation changed from $91,5 \%$ to $94,4 \%$. When they were asked about previous cornea transplant solicitation, the answer was positive at 4,8\% of the tests and increased only to 5,5\% after the campain. Conclusion: Doctors and medical students are not prepared to deal with the multiple aspects of the cornea transplant procedure. And although needed, isolated actions as informative campains are not enough to change this reality.

Keywords: Corneal transplantation, Tissue donors; Waiting lists; Health Knowledge, attitudes, practice; Questionnaires

\section{REFERÊNCIAS}

1. Arensten JJ. Laibson PR. Surgical management of pseudophakic corneal edema: Complications and visual results following penetrating keratoplasty. Ophthalmic Sug. $1982 ; 13: 371-3$ 
2. Rodrigues AM, Sato EH. Conhecimento e atitude da população do Hospital São Paulo sobre doação de córneas. Arq Bras Oftalmol. 2002; 65(6):637-40.

3. Farge EJ, Silverman ML, Khan MM, Wilhelmus KR. The impact of state legislation on eye banking. Arch Ophtalmol. 1994; 112(2):180-5.

4. Saude.gov.br [homepage na internet]. Brasília: Ministério da Saúde; c1997 [atualizada constantemente; acesso em 2007 Jan 27]. Lista de espera [aproximadamente 2 telas]. Disponível em: http://dtr2001.saude.gov.br/transplantes/

5. McGough EA, Chopek MW. The physician's role as asker in obtaining organ donations. Transplant Proc. 1990; 22(1):267-72.

6. Alves MR, Crestana FP, Kanatani R, Cresta FB, José NK. Doação de córnea: opinião e conhecimento de médicos intensivistas do Complexo Hospital das Clínicas da Faculdade de Medicina da Universidade de São Paulo. Rev Med (Sao Paulo). 1997; 76(6):315-9.

7. Saude.pr.gov.br [homepage na internet]. Curitiba: Secretaria Estadual da Saúde do Paraná; c2003- [atualizada constantemente; acesso em 2006 Oct 19]. Central de Transplantes do Paraná [aproximadamente 2 telas]. Disponível em: http://www.saude.pr.gov.br/Transplante/
8. Mack JR, Mason P, Mathers WD. Obstacles to donor eye procurement and their solutions at the University of Iowa. Cornea. 1995; 14(3):249-52.

9. Ishay R. Eye donation - how to maximize procurement. Isr J Med Sci. 1991; 27(2):89-91. Comment on: Isr J Med Sci. 1991; 27(2):79-81.

10. Ferreira U, Fregonesi A, Scafi CRF, Bachega EB, Lima ML, Netto Júnior NR. Doação de órgãos: qual é a realidade? J bras Urol. 1998 Jan/Mar; 24(1):19-22.

\section{ENDEREÇO PARA CORRESOPONDÊNCIA: \\ Manuela Fiorese Benites \\ Rua Gastão Câmara, 644 - Apto 72 \\ CEP 80730-300 - Curitiba - PR \\ mfbenites@yahoo.com.br}

